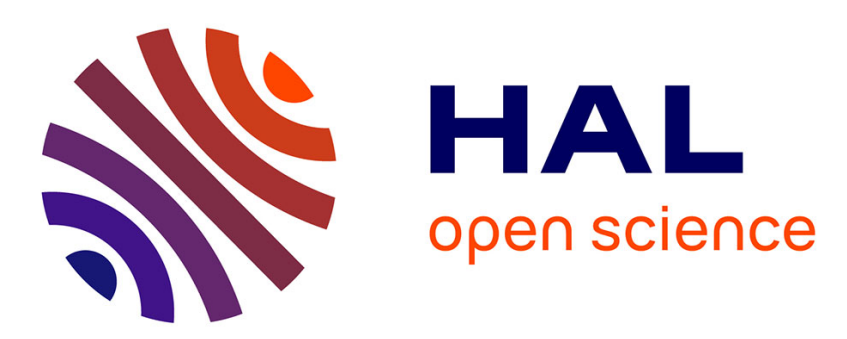

\title{
Elastic and Dissipative Properties of Solid C60
}

\author{
Ya. Soifer, N. Kobelev, I. Bashkin, A. Moravsky, E. Ponyatovsky
}

\section{To cite this version:}

Ya. Soifer, N. Kobelev, I. Bashkin, A. Moravsky, E. Ponyatovsky. Elastic and Dissipative Properties of Solid C60. Journal de Physique IV Proceedings, 1996, 06 (C8), pp.C8-621-C8-624. 10.1051/jp4:19968133 . jpa-00254565

\section{HAL Id: jpa-00254565 https://hal.science/jpa-00254565}

Submitted on 1 Jan 1996

HAL is a multi-disciplinary open access archive for the deposit and dissemination of scientific research documents, whether they are published or not. The documents may come from teaching and research institutions in France or abroad, or from public or private research centers.
L'archive ouverte pluridisciplinaire HAL, est destinée au dépôt et à la diffusion de documents scientifiques de niveau recherche, publiés ou non, émanant des établissements d'enseignement et de recherche français ou étrangers, des laboratoires publics ou privés. 
JOURNAL DE PHYSIQUE IV

Colloque C8, supplément au Journal de Physique III, Volume 6, décembre 1996

\title{
Elastic and Dissipative Properties of Solid $\mathbf{C}_{60}$
}

\author{
Ya.M. Soifer, N.P. Kobelev, I.O. Bashkin, A.P. Moravsky and E.G. Ponyatovsky \\ Institute of Solid State Physics, Russian Academy of Sciences, 142432, Chernogolovka, Moscow region, \\ Russia
}

\begin{abstract}
Elastic and dissipative properties of solid $\mathrm{C}_{60}$ in the face centered cubic (fcc) and high pressure induced phases were measured on the same specimens. The high pressure phase was synthesized in our experiments by the thermobaric treatment of specimens at temperature of $350^{\circ} \mathrm{C}$ and under pressure of $2 \mathrm{GPa}$. The structure investigations revealed the origination of the chemical bonding between $\mathrm{C}_{60}$ molecules in that phase. The measurements of attenuation and velocities of longitudinal and transverse sound waves were carried out in the temperature range from 4.2 to $300 \mathrm{~K}$ at the frequencies of 5 and $10 \mathrm{MHz}$ by echo pulse and high frequency resonance methods. It was found that the values of elastic moduli of the new phase, measured at room temperature, appeared two times higher and their temperature dependences two times weaker than corresponding ones of the pristine $\mathrm{C}_{60}$. The internal friction spectrum of fec phase differs significantly from that of hpp phase. The phenomena observed are discussed in terms of model taking into account the formation of polymer chains in the structure of the new pressure-induced phase of solid $\mathrm{C}_{60}$.
\end{abstract}

\section{INTRODUCTION}

The experimental study of solid $\mathrm{C}_{60}$ has shown that it normally forms in the face-centered cubic (fcc) phase at ambient conditions which transforms to the simple cubic (sc) phase on cooling below $260 \mathrm{~K}$ $[1,2,3]$. However although $\mathrm{C}_{60}$ molecules are extremely stable at ambient conditions, quasihydrostatic pressure induces transformations to other phases. The new high pressure phases (hpp) are suggested to originate from a different kind of $\mathrm{C}_{60}$ polimerization, that is an origination of $\mathrm{sp} 3$ bondings $[4,5]$. The lowest reported pressure for occurence of such $\mathrm{C}_{60}$ transformation is about $7 \mathrm{kbar}$ at $620 \mathrm{~K}$. This new phase was retained to ambient conditions and therefore could be investigated by different techniques. The phase was more dense that the pristine solid $\mathrm{C}_{60}$ by at least $8.5 \%$ and less compressible. The main feature of the structure which was determined with certainty is the value of the nearest distance between the centers of $\mathrm{C}_{60}$ molecules. It proved to be equal $9.2 \mathrm{~A}$, that according to calculations [6] means that along this direction the chemical bonding between $\mathrm{C}_{60}$ molecules should occur. This conclusion is confirmed by the fact that this phase is absolutely insoluable in toluene.

This paper presents the results of the experimental studies of elastic and dissipative properties of the solid $\mathrm{C}_{60}$ in the (fcc) and high pressure induced phases measured on the same samples but in the different structural states.

\section{EXPERIMENTAL}

The measurements were performed on the cylindrical samples of $8 \mathrm{~mm}$ diameter and from 2 to $3 \mathrm{~mm}$ thick compacted at room temperature by uniaxial compression to $\approx 1 \mathrm{GPa}$. A high purity powder obtained by a procedure described elsewhere $[4,5,7]$ was used. The fcc crystal structure $(a=14.17 \mathrm{~A})$ was determined by X-ray diffraction. The grain size was about $1 \mathrm{mkm}$ and the sample density was $\approx 1.62 \mathrm{~g} / \mathrm{mm}^{2}$. To obtain a new phase the samples were subjected to a thermobaric treatment at the temperature of $620 \mathrm{~K}$ and pressure of $2 \mathrm{GPa}$ followed by quenching under pressure to room temperature. The X-ray diffraction patterns of all specimens thus obtained corresponded to the new high pressure phase[5,8]. The grain size was $\approx 1 \mathrm{mkm}$ and the sample density was about $1.76 \mathrm{~g} / \mathrm{cm}^{2}$.

Two acoustic techniques were used to determine the elastic moduli. The longitudinal and transverse sound velocities, $v_{L}$ and $v_{S}$, were measured at room temperature with the accuracy of 
$\approx 2 \%$ using echo-pulse method modified for the small specimens. A high-frequency resonance method [7] was applied to measure an attenuation and the relative sound velocity change in dependence on temperature. The measurements were performed with $\mathrm{LiNb}_{3} \mathrm{O}_{3}$ transducers at frequencies of $\approx 5$ and $\approx 10 \mathrm{MHz}$.

The longitudinal and shear moduli, $C_{y}$, and $\left({ }^{\prime}\right.$, were calculated from the sound velocities according to the well-known relations: $C_{L}=\rho v_{L}{ }^{2}$ and $\mathrm{G}=\rho \mathrm{v}_{s}{ }^{2}$. Other moduli, i.e. bulk modulus $\mathrm{K}$, Young's modulus $\mathrm{E}$ and Poisson's ratio ", were obtained from relations between the elastic moduli of an isotropic medium: $\mathrm{K}=\mathrm{C}_{L}-(4 / 3) \mathrm{G}_{,} \nu=\left(\mathrm{C}_{L}-2 \mathrm{G}\right) /\left(2 \mathrm{C}_{L}-2 \mathrm{G}\right)$ and $\mathrm{E}=2 \mathrm{G}(1+\nu)$.

\section{RESULTS}

In the Table the experimentally determined elastic moduli for the fcc phase and for the hpp of $\mathrm{C}_{60}$ are presented. These results were obtained on the same samples in different structural states. Here the elastic moduli of solid $\mathrm{C}_{60}$ calculated [9] on the basis of a modified Buckingham potential also are given. The theoretical values of $\mathrm{K}, \mathrm{E}$ and ( $\mathrm{B}$ were obtained by Hill's averaging [10] for the elastic constants calculated for fcc structure of $C_{60}[9]$.

Table

The experimentally measured and calculated elastic morluli of solid $\mathrm{C}_{60}(300 \mathrm{~K})$.

\begin{tabular}{|c|c|c|c|c|}
\hline & $\mathrm{E}, \mathrm{GPa}$ & $\mathrm{K},{ }_{\mathrm{C}}{ }_{\mathrm{r} a}$ & $\mathrm{G}, \mathrm{G} \mathrm{Ga}$ & \\
\hline fcc phase & 13.4 & 9.0 & 5.4 & theory [9] \\
\hline fcc phase & 9.8 & 8.4 & 3.8 & experiment \\
\hline new phase & 25.2 & 23.8 & 9.5 & experiment \\
\hline
\end{tabular}

The temperature dependences of the velocity $V_{L}(T)$ and internal friction $Q^{-1}(T)$ in the sample with fec structure measured at 5 and $10 \mathrm{MHz}$ are shown in the Fig.1. Two internal friction peaks at $250 \mathrm{~K}$ and $210 \mathrm{~K}$ at $5 \mathrm{MHz}$ and corresponding changes in velocities are observed.

The temperature dependences of the internal friction $Q^{-1}$ and the longitudunal sound wave velocity for pressure-induced phase are presented in Fig.2. The are no noticeable changes in $V_{L}(T)$ and $\mathrm{Q}^{-1}(\mathrm{~T})$ near the temperature of $250 \mathrm{~K}$ where orientational ordering transition occurs in the case of pristine phase of solid $\mathrm{C}_{60}$. Some pecularities of internal friction spectrum and corresponding velocity changes at $\approx 180$ and $\approx 220 \mathrm{~K}$ are observed. One can see an influence of the measurement frequency on the high temperature part of the internal friction spectrum.

There is also a broad internal friction peak near $80 \mathrm{~K}$.

The full change of sound velocity between 300 and $4.2 \mathrm{~K}$ for the new phase was about $12 \%$ for longitudinal and about $17 \%$ for transverse sound wave. Thus the temperature dependence of elastic moduli for the new phase is about two times weaker than that is for the fcc-sc phase.

\section{DISCUSSION}

Let us consider the results obtained taking into account the preliminary data on structure of the hpp-phase [8]. As one can see from the Table the elastic moduli of the $\mathrm{C}_{60}$ fcc phase are in a good agreement with the theoretical ones, which were calculated on the basis of the intermolecular potentials. However the elastic moduli of the $C_{60}$ hpp phase are two and a half times higher than corresponding ones for the pristine fcc phase. It means that the new hpp phase lattice of solid $\mathrm{C}_{60}$ is much stiffer than fcc phase lattice which agrees well with the suggestion as to the origination of sp3 bonding. This conclusion is confirmed also by the comparision of the temperature dependences of elastic moduli of fcc and hpp phase. The temperature dependence is about two times weaker in hpp phase than in fcc one which is also in favour of the assumption made.

The temperature dependences of internal friction and sound velocity variation in the fcc phase specimens are very similar to those obtained for fcc single crystals $[10,12]$. The peak at $\mathrm{T}=$ $250 \mathrm{~K}$ does not depend on the frequency and its temperature coincides with the temperature of the ordering phase transition from fcc to sc described elsewhere $[1,2,3]$.

The second peak observed at $T=210 \mathrm{~K}$ depends strongly on the frequency and the $V(T)$ curves manifest distinctive variations near the peak temperature. This peak can be described by the Debye relaxation process with the activation parameters: $U \approx 0.3 \mathrm{eV}$ and $\tau_{0} \approx 10^{-14} \mathrm{~s}$, where $U$ is the activation energy of the process and $\tau$ is the relaxation time. It is considered that this relaxation process is due to the reorientation jumping of the $\mathrm{C}_{60}$ molecules between different orientations in the sc lattice. 

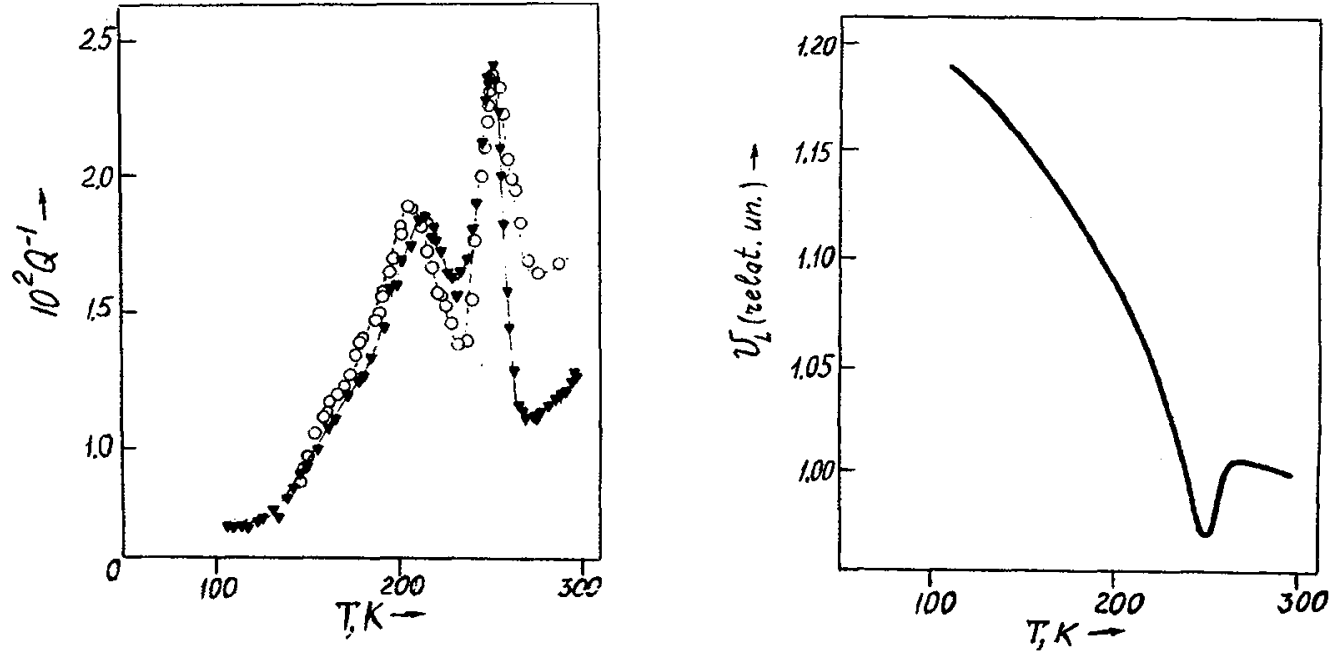

Fig.1: Temperature dependences of internal friction in fcc-sc phase of $\mathrm{C}_{60}$ at the frequencies of $5 \mathrm{MHz}$ (circles) and $10 \mathrm{M} \mathrm{Hz}$ (full triangles) and the corresponding variation of sound wave velocity ( $5 \mathrm{MHz}$ ). Longitudinal waves.
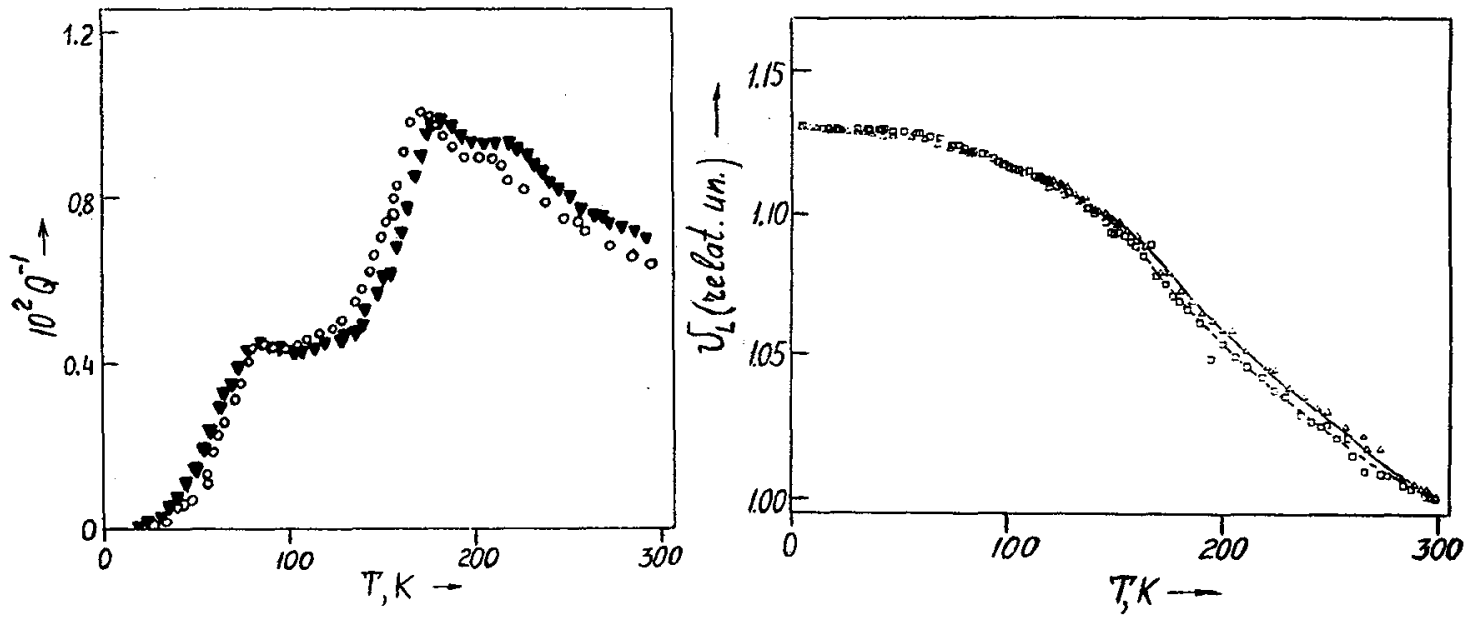

Fig.2: Temperature dependences of internal friction and the corresponding sound velocity variation in the pressure-induced phase of $\mathrm{C}_{60}$. Longitudinal waves. Circules and squares $-5 \mathrm{MHz}$, full and empty triangles $.10 \mathrm{MHz}$ 
The temperature dependences of internal friction and sound wave changes for hpp phase differ significantly from those for fcc phase. There are no distinctive peaks; nevertheless one can consider the internal friction spectrum $\mathrm{Q}^{-1}(\mathrm{~T})$ as a superposition of a number of the separate peaks. The fact that the variation of frequency influences part of the internal friction spectra (a shift to high temperature when frequency increases, Fig.2) allows us to assume a relaxation nature of some internal friction peaks which are components of the spectrum. A rough estimation of the possible relaxations parameters give the energy activation $U$ values from 0.2 to $0.3 \mathrm{eV}$ and the relaxation time $\tau_{0}$ from $10^{-13}$ to $10^{-14} \mathrm{~s}$.

One of the probable explanations of the internal friction found in $\mathrm{C}_{60}$ hpp samples is most likely to be connected with those changes in the lattice structure that have occurred under high pressure. X-ray and neutron diffraction measurements show that high pressure transforms $\mathrm{C}^{60} \mathrm{fcc}$ lattice to an orthorhombic one where each molecule is bonded to the two nearest neighbours along a [100] fcc direction forming parallel chains. By analogy with crystalline polymers one can propose that in such structure different kinds of temperature dependent rotation mobility of the polymer chains are possible that can lead to relaxation phenomena and internal friction peaks correspondingly. However the relaxation times of relaxation processes in conventional cristalline polymers are much larger than those found in the present experiments. To overcome this discrepancy one has to assume the existence of a number of short (less than $10 \mathrm{~nm}$ ) freely rotating (around polymer axis) polymer segments. Such assumption does not scem unrealistic taking into account imperfect conditions of the polymerization process that can lead to terminated polymer chains. Thus the polymer structure formed will differ from an ideal one by a great number of uncorrelated ruptures of chemical bonds. In that case the structure will consist of polymer segments of different lengths having the ability for rotation movement. One of the way to examine the assumption made is to study the samples subjected to different kinds of the heal treatments.

As to the low temperature (below $100 \mathrm{~K}$ ) acoustic anomalies, if the approach given above is valid, they can be connected to the orientational "glass-like" transition due to the "freezing" of the rotation motion.

\section{Acknowledgments}

This work was supported by the Russian Research Program "Fullerenes and Atomic Clusters".

\section{References}

[1] Heiney R.A., Fischer J.E., McGhiel A.R., Romanow W.J., Denenstein A.M., McCauley J.P.Jr, Smith A.B. III, Cox D.E., Phys.Rev.Lett. 66 (1991) 2911-2914.

[2] AtakeT., Tanaka T., Kawaji H., Kikuchi K., Saito K., Suzuki S., Ikemoto I., Achiba Y., Physica C 185-189 (1991) 427-434.

[3] Kriza G., Ameline J.-C., Jerome D., Dworkin A., Szwarc H., Fabre C., Schultz D., Rassat A., Bernier P., Zahab A., J.Physique I I (1991) 1361-1364.

[4] BashkinI.O., Rashchupkin V.I., Kobelev N.P., Moravsky A.P., Soifer Ya.M., Ponyatovsky E.G., Sov.Phys.-JETP Lett. 59 (1994) 258-261.

[5] Bashkin I.O., Rashchupkin V.I., Gurov A.F., Moravsky A.P., Rybchenko O.G., Kobelev N.P., Soifer Ya.M., Ponyatovsky E.G., J.Phys.:Cond.Matter 6 (1994) 74-91.

6] Adams G.B., Page J.B., Sankey O.F., O'Keeffe M., Phys.Rev.B 50 (1994) 17471-17477.

7] Kobelev N.P., Moravsky N.P., Soifer Ya.M., Bashkin I.O., Rybchenko O.G., Fiz.Tverd.Tela 36 (1994) 2732-2737.

[8] Moravsky A.P., Abrosimova G.E., Bashkin I.O., Dilanyan R.A., Gurov A.F., Kobelev N.P., Rashchupkin V.I., Rybchenko O.G., Soifer Ya.M., Shekhtman V.Sh., Ponyatovsky E.G., "Fullerenes: recent advances in the chemistry and physics of fullerenes and related materials", V.2, R.S.Ruoff and K.M.Kadish Eds. (Electrochem. Society, Pennington, N.J, 1995) pp.952-963.

[9] Burgos E., Halas E., Bonadeo H., Phys.Rev.B 49 (1994) 15544-15550.

10] Hill R.W., Proc.Phys.Soc. (London) A65 (1952) 349-355.

11] Shi X.D., Kortan A.R., Williams J.M., Saval A.M., Chaikin P.M., Phys.Rev.Lett. 68 (1992) 827 830.

[12] Schranz W., Fuith A., Dolinar P., Wabanek H., Halushka M., Kuzmany H., Phys.Rev.Lett. 71 (1993) 1561-1654. 